\title{
Os dilemas da metafísica segundo Charles Renouvier
}

\author{
Metaphysical Dilemmas according to Charles Renouvier
}

\author{
Katia Santos \\ katiasantosfilo@gmail.com \\ (Universidade de São Paulo, São Paulo, Brasil)
}

\begin{abstract}
Resumo: Este texto apresenta e discute a concepção de Charles Renouvier sobre dilemas metafísicos na História da Filosofia. Com base no seu princípio de relatividade, esse pensador analisa as filosofias mais influentes ao longo da História, apontando as inconsistências e dilemas presentes nas teorias das metafísicas realistas. Neste artigo, acompanhamos as dicotomias explanadas na obra Les dilemmes de la métaphysique pure, com o objetivo de destacar as questões filosóficas que estão no fundamento dos dilemas e ressaltá-las como fio condutor da análise histórica de Renouvier.
\end{abstract}

Palavras chaves: Charles Renouvier; dilemas metafísicos; neocriticismo; princípio de relatividade.

\begin{abstract}
This text presents and spars Charles Renouvier's notions on metaphysical dilemmas in the History of Philosophy. Based on his principle of relativity, this thinker analyzes the most influent philosophies throughout History, pointing out the enclosed contradictions and dilemmas on the theories of realistic metaphysical theories. In this article, we keep track of the outlined dichotomies of Les dilemmes de la métaphysique pure, with the aim to emphasize the philosophical questions that are on the dilemmas rationales and reinforce them as a common thread of Renouvier's historical analysis.
\end{abstract}

Keywords: Charles Renouvier; metaphysical dilemmas; neocriticism; principle of relativity.

DOI: http://dx.doi.org/10.11606/issn.2318-9800.v25i1p89-104

\section{Introdução}

Cependant aucune thèse capitale ne se laisse complètement expulser du domaine de la métaphysique.

Renouvier

Charles Renouvier é conhecido por ser o principal filósofo do neocriticismo e pelas suas ideias políticas e morais, forjadas durante os acontecimentos da França do século XIX (Blais, 2000). Ele participou ativamente da Revolução de 1848 e contribuiu teoricamente com diversas discussões, ${ }^{1}$ até o golpe de Luís Bonaparte, em 1851,

1 Cf.: Renouvier (1848); Renouvier et al. (1851); Renouvier \& Pillon (1872-1889); diversos artigos na Feuille du Peuple, de 1850 a 1851. 
quando sua desilusão o levou a se dedicar quase integralmente à Filosofia. ${ }^{2} \mathrm{~A}$ atividade teórica de Renouvier tem diversas facetas, volta-se para diferentes questões que vão desde a política e a moral até a teoria do conhecimento e a metafísica. Mas há ainda outro traço da sua investigação especialmente importante para a discussão que pretendemos fazer neste artigo, a saber, sua atividade de historiador da Filosofia. De fato, desde as suas primeiras obras, está presente a preocupação de compreender a História da Filosofia de modo sistemático. Em 1842, ele publica Manuel de philosophie moderne; em 1844, o Manuel de philosophie ancienne; em 1885 aparece Esquisse d'une classification systématique des doctrines philosophiques, publicado anteriormente em fascículos; em 1864, surge Introduction a la philosophie analytique de l'histoire, o quarto dos seus Essais de critique générale, reeditado em 1896; e, em 1901, Histoire et solution des problèmes métaphysiques. Sobre esse aspecto, Octave Hamelin, discípulo do filósofo, afirma no texto La philosophie analytique de l'histoire de M. Renouvier, escrito para a revista editada por Renouvier e F. Pillon, L'Anée Philosophique, referente ao ano de 1898: "a própria crítica literária tem seu tempo. Enfim, a esse vasto conjunto dogmático se juntam os estudos históricos" (Hamelin, 1899, p. 21). ${ }^{3}$

No presente artigo, nosso interesse se volta para a discussão contida numa obra de maturidade de Renouvier, em que se pode refletir sobre sua compreensão acerca de questões fundamentais da tradição filosófica. Em Les dilemmes de la métaphysique pure, publicado em 1901, sua análise da História da Filosofia revela dilemas metafísicos, os quais, no seu entendimento, não podem ser resolvidos com recurso apenas à racionalidade. Para além da simples adoção de uma posição positivista, ${ }^{4}$ Renouvier considerava que os problemas metafísicos tradicionalmente abordados na Filosofia recaem fora do alcance do conhecimento humano, por não se apresentarem em nenhuma relação e não serem passíveis de demonstração. Para ele, o caminho para se acessar a metafísica não é o conhecimento teórico, mas a natureza moral do ser humano, de modo que a razão prática deve se sobrepor à teórica.

Nesse sentido, a História da Filosofia seria palco de disputa entre sistemas contraditórios, cujo estudo seria uma propedêutica para o mais importante, a reflexão sobre a questão moral. Renouvier defende a liberdade e a individualidade e critica o determinismo e anulação do indivíduo, entendendo que o destino moral é o verdadeiro fundamento da vida humana. A investigação que ele realiza na História da Filosofia revela então dicotomias entre os modos como as noções de condição,

2 Dizemos quase integralmente porque Renouvier nunca deixou de refletir acerca das questões políticas e morais da França de seu tempo. Para uma discussão da relação entre o neocriticismo e as posições políticas do filósofo, cf.: Fedi (2002).

3 Todos os textos citados neste artigo foram traduzidos por nós.

4 Para uma discussão da relação de Renouvier com as teses positivistas, cf.: Schmaus (2007). 
qualidade, quantidade, causalidade e personalidade são aplicadas ao mundo pelas metafísicas realistas, de um lado, e pelo neocriticismo, de outro. Com efeito, o realismo afirma a realidade do incondicionado, da substância e do infinito, bem como o determinismo e o impersonalismo, enquanto o neocriticismo, baseando-se no que ele define como princípio de relatividade, advoga o condicionado, o finito, o personalismo e a liberdade.

\section{O princípio de relatividade}

Renouvier considera a crítica do conhecimento nos moldes kantianos como uma das realizações mais importantes da Filosofia. Porém, como mostra Laurent Fedi, ele não adota integralmente as posições de Kant:

Renouvier inicia, desde 1854, a situar o problema do conhecimento sobre a esteira do kantismo, e declara: "Eu confesso abertamente que continuo Kant" (Prefácio de 1854, Log., XIV). Paralelamente, Renouvier considera que o sistema de Kant é frequentemente infiel ao espírito da crítica e que convinha, em consequência, reformá-lo (Fedi, 1998, p. 14). ${ }^{5}$

Embora não tenha sido formulado expressamente por Kant, o filósofo entende que o princípio de relatividade é derivado do pensamento kantiano. Para compreender o princípio, no entanto, é necessário levar em conta suas definições de sujeito e objeto, as quais são diferentes das de Kant. Com efeito, Renouvier elabora sua visão acerca do subjetivo e do objetivo tanto contra o que entende como um falso idealismo, quanto contra o positivismo. O falso idealismo seria responsável pela dúvida sobre a realidade externa, e o positivismo pela desconfiança acerca do subjetivo, onde se enquadrariam inclusive as ideias e a moral (Renouvier, 1901a/1927, p. 7). ${ }^{6} \mathrm{Na}$ sua concepção, sujeito é a consciência empírica e intuitiva que o "eu” tem de si mesmo, dada na memória e na ligação interna das representações. Trata-se de uma função dos fenômenos que se apresenta a nós por si mesma e que constitui um fato. Podemos tomá-la como real, ele afirma, sem precisar introduzir o problema de sua substancialidade ou permanência, e devemos reconhecê-la como condição de possibilidade da representação de qualquer objeto (idem, pp. 7-8). Por sua vez, para além do que é na representação, o objeto será admitido na condição de crença. Nas palavras dele,

A ideia do objeto exterior é certa, como sendo ela mesma um dado empírico, e é verdadeira, como crença da qual é impossível à nossa consciência se desfazer. Para distingui-la da noção de exterioridade, ou intuição espacial, que é apenas uma forma sensível, ela poderia ser chamada, com razão, de noção de alteridade (idem, p. 6, itálicos do autor).

5 Sobre a posição de Renouvier com relação a Kant, cf. Renouvier (1906) e Verneaux (1945).

6 Edição citada: Paris: Alcan, 1927. 
Além do sujeito como consciência empírica, Renouvier admite ainda outro conceito. De acordo com ele, alguns objetos da consciência se convertem em sujeitos para si e, com isso, em seres reais, devendo ser estudados nos seus próprios atributos e funções, e nas relações mútuas que estabelecem. Essas características seriam diferentes e separadas daquelas pelas quais eles são objetos para nós. A alteridade e a distinção que todos possuem entre si, diz o filósofo, são os motivos pelos quais devem ser considerados sujeitos e não meramente objetos, e que permitem definilos conforme qualidades determinadas, das quais são sínteses (idem, ibidem). Fedi observa corretamente que se trata aqui de um ponto essencial, que nunca foi apontado pelos comentadores (1998, p.22). De fato, a questão se liga ao problema da realidade externa e à necessidade de impedir a caída no solipsismo. Com efeito, Renouvier enfatiza que o procedimento de denominar sujeito à consciência do "eu" foi enganoso, porque levou a identificar todos os outros sujeitos com objetos. Como consequência dessa denominação, subjetivo se tornou o que se refere ao "eu" e objetivo o que se refere aos objetos da experiência, conduzindo então à dúvida quanto à realidade do que se encontra fora do sujeito e à objetividade das suas representações. Para evitar isso, ele escreve, "voltaremos a uma terminologia mais natural. Chamaremos subjetiva toda qualidade constitutiva de um sujeito qualquer, ou que pertença à sua natureza definida; e objetiva a toda representação, enquanto dada a uma consciência como seu objeto, interno ou externo que se suponha" (1901a, p. 7, itálicos do autor). A partir daí, Renouvier deduz sua tese da realidade (thèse de la réalité), segundo a qual sujeito real é o objeto representado que possui a forma subjetiva, ou seja, é um sujeito de qualidades e relações, e não um mero atributo de outros sujeitos, e que se define por relações internas ou externas, regidas pelas leis do entendimento (idem, p. 9).

0 princípio de relatividade é formulado à luz dessas definições: "Segundo esse princípio, a natureza do espírito é tal, que nenhum conhecimento pode ser alcançado e formulado e, consequentemente, nenhuma existência real pode ser concebida, senão com base em suas relações e, em si mesma, como um sistema de relações" (idem, p. 11, itálicos do autor). No artigo Du principe de relativité, publicado na edição referente ao ano de 1898 da L'Anée Philosophique, Renouvier detalha o sentido do princípio de relatividade. Ele afirma que o conhecimento é duplamente relativo, pois depende da constituição do entendimento humano, de um lado, e, de outro, da individualidade do pensador, com sua constituição física, moral, suas paixões e vontades (1899, pp. 1-3). Nessa concepção, que ele chama de fenomenismo, a consciência pessoal acompanha a representação das coisas externas, e o fenômeno é constituído pelas relações que formam as impressões, percepções e juízos (idem, p. 14). Como ele escreve, "o princípio de relatividade convém a ele [ao fenomenismo], portanto, essencialmente; o neocriticismo reclama a aplicação ao conhecimento, à 
definição dos seres de toda natureza; ele só os considera definíveis como sínteses e funções determinadas de fenômenos" (idem, ibidem).

O princípio de relatividade se torna, então, o método de investigação e julgamento da História da Filosofia, na qual o erro e as contradições mútuas entre as teorias filosóficas aparecem como fatos. Nós erramos e nos contradizemos mutuamente no tocante a questões de grande interesse religioso e filosófico, questões que, escreve Renouvier, "têm logicamente na sua dependência os juízos gerais sobre a natureza das coisas e sobre a causa dos fenômenos" (idem, p. 2). 0 princípio de relatividade será o instrumento da análise e resolução dessas questões, por meio da sua aplicação aos resultados das metafísicas mais importantes. No prefácio de Introduction a la philosophie analytique de l'histoire (1896), ele resume sua concepção de forma lapidar:

Apenas o criticismo, que é uma filosofia da crença racional, encontra-se no ponto de vista que permite classificar e julgar os produtos da inteligência e da paixão humana aplicados ao curso dos séculos, para penetrar a verdade que escapa à certeza, com o fim de regular sua vida, criar suas instituições, e preparar seus esplendorosos futuros conforme o que pensa e crê, ou espera de si mesmo e da ordem do mundo (Renouvier, 1896, p. III).

\section{Os dilemas metafísicos}

Renouvier define dilema metafísico como um antagonismo entre duas teses filosóficas, no qual uma é a negação da outra com todas as suas implicações, sem refutação possível de uma pela outra. No seu entender, do ponto de vista lógico, seria necessário aceitar-se uma das duas teses como verdadeira; no entanto, a escolha entre os lados opostos envolve uma atitude de negação ou afirmação do conteúdo delas, isto é, uma decisão não meramente lógica. Como dissemos antes, os dilemas se referem às noções metafísicas de condição, qualidade, quantidade, causalidade e personalidade, às quais correspondem as dicotomias que opõem o condicionado e o incondicionado, a substância e a lei dos fenômenos, o finito e o infinito, o determinismo e a liberdade, e a coisa e a pessoa.

Sobre o primeiro dilema, Renouvier afirma que o incondicionado é o produto mais antigo do realismo, exposto na teoria do ser de Parmênides com a concepção de um sujeito único e universal, que é ao mesmo tempo a ideia mais geral e abstrata. Nessa teoria, pensamento e ser são idênticos, sem distinção entre sujeito e objeto e, além disso, o ser é tomado como origem de todas condições, imutável, indivisível e ilimitado (idem, p.14). Adotada por escolas teológicas antigas e medievais, essa doutrina foi desenvolvida na concepção do Uno puro, sem atributos, que estaria acima da experiência. Segundo Renouvier, a explicação do modo como o 
incondicionado originaria o condicionado foi pensada muitas vezes como emanação, porque isso possibilitava isolá-lo em sua dignidade. O Bem de Platão, o pensamento que se objetiva a si mesmo, de Aristóteles, o Primeiro Deus dos gnósticos, a Primeira Hipóstase dos neoplatônicos e, por fim, a teologia cristã, seriam todos variedades da doutrina do Uno (1901a, pp. 16-17). Na Idade Moderna, muitos sistemas também tiveram o incondicionado como ponto de partida e a emanação como uma de suas características. Com efeito, o problema de situar a procedência das condições é o que teria originado o "eu" de Fichte, o incondicionado de Schelling e Hegel. ${ }^{7}$

Para Renouvier, na base das teorias do incondicionado está a necessidade de se apoiar o mundo condicionado sobre um fundamento não condicionado. Como ele explica, "sem isso, o relativo nunca se relacionando senão com o relativo, em última análise, todas as relações se apoiariam sobre o nada" (idem, p. 50). A afirmação de um ser necessário, que existiria em si e por si, foi a forma encontrada para resolver essa questão. Entretanto, diz ele, toda tentativa de partir do incondicionado para deduzir o condicionado enfrenta um vício lógico inerente: "é que é necessário que o primeiro seja qualificado de alguma forma, ou suposto capaz de qualquer ação, para que algo dele seja representado no segundo, na natureza, o que parece dever estabelecer nele relações, condições" (idem, p. 20). Na verdade, tudo o que se puder afirmar do incondicionado terá de ser extraído das condições, às quais, não obstante, ele deveria ignorar e das quais deveria ser o fundamento (idem, p. 47). Por meio da ideia de emanação, o incondicionado ao seria conectado ao condicionado mediante gradações; porém, duas graves dificuldades surgiriam também desse procedimento, a saber, a de relacionar o incondicionado com o fenômeno da vida e do bem, e a de apontar o início do condicionamento no tempo. Para Renouvier, de um lado, há um abismo intransponível entre o incondicionado e a vida, e, de outro, a origem do condicionado no tempo não pode ser encontrada. Para iludir o caráter insolúvel dessa última questão, a origem teria sido recuada a um passado infinito, pois, caso se apontasse a existência do incondicionado em um dado momento, ele teria de ser tomado como condicionado, como todas as coisas (idem, p. 49).

De acordo com isso, o dilema do incondicionado coloca em oposição a dedução do mundo a partir de um ser incondicionado, independente de relações, e o princípio de relatividade. A tese do condicionado, baseada no princípio, afirma que o mundo é constituído em relações internas pelas mesmas leis que regem o intelecto. Essa concepção, porém, não implicaria que a série de condições terminasse no nada, nem que a ideia de causa do mundo devesse ser eliminada. Na verdade, diz Renouvier, as causas eficiente e final são as duas grandes relações constitutivas do pensamento

7 É muito interessante notar que Renouvier entende a questão da coisa em si e sua afecção sobre os sentidos, surgida e debatida na recepção da filosofia kantiana, como um caso das contradições intrínsecas a todas as teorias do incondicionado. 
(idem, p. 51). Assim, na tese do condicionado, o mundo "é um círculo de propriedades que se fecha e cujas relações internas aparecem em uma unidade sintética para uma inteligência capaz de abarcá-las" (idem, ibidem). Por conseguinte, a escolha que se abre é a de se recusar ou se aceitar do princípio de relatividade como o único capaz de conduzir à definição do sujeito último (idem, p. 54). Como o filósofo escreve,

As duas teses são contraditórias: a primeira exige, com efeito, que toda coisa seja concebida por meio das suas relações com as outras, em uma função dos fenômenos ligados pelas leis do conhecimento em nós; a segunda pretende que a essência do sujeito seja investigada em si, na maior abstração possível das qualidades e relações dos fenômenos, até que ela se encontre enfim expressa pelos termos gerais que se realizem e que, ao fim, representem o Incondicionado por uma negação (idem, pp. 53-54, itálicos do autor).

O segundo dilema se refere à oposição entre a substância e as leis dos fenômenos. Conforme Renouvier, a primeira noção de substância se referia a uma matéria confusa, da qual os corpos diferenciados teriam se originado, nomeada Caos por Hesíodo, na sua Teogonia. Das tentativas de definir essa matéria teriam surgido diferentes teorias, dentre as quais a de Anaximando seria a mais simples e melhor do que a maioria. Nela, a substância é pensada no sentido mais abstrato e universal como um sujeito composto de elementos qualitativos infinitos, ao qual também corresponde um poder ativo de compor e decompor os corpos. O filósofo observa que a concepção do infinito que consta na teoria de Anaximando é a de um ilimitado no sentido de extensão e vastidão potenciais, e não a de um ente composto de uma infinidade atual de elementos. Além disso, Anaximandro teria dado um passo fundamental, ao considerar, pela primeira vez, o princípio como sendo um sujeito não material. Nas palavras de Renouvier, "é o hypokeímenon, é o sujeito ele mesmo que é a Arché: a fórmula poderia, assim, ser traduzida como uma extraordinária correção metafísica realizada na ideia física da água, de Tales, mestre de Anaximandro" (idem, p. 57).

A concepção platônica de substância preservaria a ideia de uma massa indistinta de elementos que forma o sujeito dos fenômenos sensíveis. Mas há uma diferença fundamental, qual seja, a de não atribuir a ela o princípio de suas próprias mudanças. Segundo Renouvier, Platão a pensou, mais propriamente, como o receptáculo comum das formas, de onde elas procedem e para onde retornarão, e como um ser indefinível. Como ele afirma, tal ser "não foi diferenciado por esse último [Platão] do espaço, teatro das aparências, era menos um sujeito do que o conceito do lugar onde as ideias e os números se tornam participáveis às almas" (idem, p. 70). Descartes, por sua vez, teria proposto uma dicotomia na classificação dos fenômenos, entendidos como referentes ou à atividade psíquica ou à matéria, sem estabelecer uma causa. Com esse procedimento simples e eficaz, escreve Renouvier, “Descartes dava ao substancialismo, por essa divisão perfeitamente clara de duas 
ordens de fenômenos cujas realidades respectivas não são negadas, um fundamento real, em lugar das antigas ficções realistas" (idem, p. 76). Ao subordinar a extensão ao pensamento, Descartes teria fundamentado a dedução de todos os fenômenos a partir da consciência, ao mesmo tempo em que teria descoberto o princípio da física mecânica.

Nesse sentido, o dilema da substância se refere à dicotomia de perspectivas existente entre o realismo substancialista e a concepção de que os objetos somente podem ser conhecidos pela compreensão dos fenômenos e suas leis. A questão de fundo no dilema da substância gira em torno de duas relações. A primeira se dá entre a consciência como sujeito e um dado fenômeno mental como objeto. A segunda ocorre entre um corpo e uma qualidade qualquer atribuída a ele conforme as leis físicas (idem, p. 94). Nas palavras de Renouvier, "esse é o ponto de vista exato da relação, conforme a categoria lógica da substância, bem como ao modo psíquico de associação da qualidade à coisa qualificada" (idem, ibidem, itálicos do autor). O dilema exige, então, a opção entre o método das relações e funções de fenômenos, segundo o princípio de relatividade, e o método realista das noções e entidades abstratas. Da perspectiva do substancialismo, existe um sujeito real ao qual são inerentes certas qualidades e do qual, de algum modo, todos os fenômenos dependem. Da perspectiva do fenomenismo, o sujeito é definido e constituído pelas suas qualidades e relações internas e pelas que mantém com outros sujeitos. Estabelece-se, pois, a seguinte dicotomia:

Ou a lei que liga as qualidades ao seu sujeito lógico implica a existência de um sujeito real, independente em si dessas qualidades e de todas as outras qualidades que podem defini-lo para o conhecimento.

Ou não existe sujeito em si, indefinível em si como objeto de conhecimento, mas todo ser real deve se definir como uma função de fenômenos unidos sob certas leis, e como o sujeito lógico de todas as relações que ele mantém e de todas as qualidades que pertencem a ele (idem, p. 98, itálicos do autor).

O terceiro dilema se refere à oposição entre finito e infinito, surgida na Antiguidade com as investigações acerca do começo do mundo. A crítica veemente ao infinitismo é um dos pilares da filosofia de Renouvier e, conforme Fedi, o momento em que ele se convence da contradição intrínseca à ideia de infinito atual marca o fim da primeira fase de sua filosofia, composta de anseios filosóficos difusos, e o início do neocriticismo. Nas palavras desse autor, "adescoberta das contradições do infinito atual, em torno de 1851, conduz ao verdadeiro sistema, o 'neocriticismo', doutrina que conjuga o fenomenismo, o finitismo e o apriorismo. Pode-se falar aqui de virada e até mesmo de conversão" (Fedi, 1998, p. 10). Na interpretação de Ernst Cassirer, a oposição entre finito e infinito é o centro da filosofia da Renouvier, que representa a principal continuação do criticismo fora da Alemanha. Conforme esse 
autor, trata-se de uma discussão derivada das antinomias da razão pura, mas na qual o caráter antinômico das oposições diminui. Para Cassirer, Renouvier decide claramente em favor da tese e defende que o finito deve ser afirmado em relação ao mundo: "finitude é o caráter de todo ser" (Cassirer, 1912, p. 86).

A disputa nessa dicotomia teria iniciado com as teses de Zenão de Eleia sobre a impossibilidade de que um móvel pudesse percorrer séries infinitas de partes, em uma extensão. Na interpretação de Renouvier, era muito clara a tese de Zenão de que “Em tudo o que não tem fim, o fim não pode ser alcançado" (1901a, p. 100, itálicos do autor). Por sua vez, a tese contrária partia da realidade da matéria, sem distinguir objetivo e subjetivo, ou potência e ato. Na sua obra La philosophie de Charles Renouvier (1927), Gaston Milhaud explica a lei do número, que é o princípio do finitismo:

Esse será o postulado fundamental da nova filosofia de Renouvier, que ele mesmo chama "a lei do número": Todas as vezes que a realidade concreta nos dá a ocasião de contar as coisas, quaisquer que sejam elas, essas coisas, não podendo ser em número infinito, o que seria contraditório, são necessariamente em número finito. (Milhaud, 1927, p. 55, itálicos do autor).

Renouvier observa que, em seu tempo, a ideia antiga de uma quantidade de magnitude indefinida, entendida como sempre suscetível de aumento, foi convertida na ideia de uma quantidade infinita realizada. Uma extensão e um número podem sempre ser acrescidos de uma unidade, ele afirma, mas essa infinitude nunca pode ser tomada como dada, na medida em que a soma das partes, inesgotáveis por definição, nunca será terminada. Com o termo árદıрos, os gregos teriam significado o ilimitado no sentido de um objeto inesgotável, sem a necessidade de se ocupar com o estado atual do número infinito correspondente. No tocante ao tempo, o ilimitado nada tinha a ver com a ideia de eternidade, e sim com a de um presente sempre atual, sem origem e não suscetível de mudança (Renouvier, 1901a, p. 102).

Aristóteles teria formulado uma teoria singular nesse tocante. Ele admitiu a necessidade de um ponto de partida na cadeia dos fenômenos, que ele apontou como sendo o Motor Imóvel, definido como a causa eterna dos movimentos inferiores subordinados. Com isso, o sistema cósmico foi unificado em uma totalidade, na qual o Motor Imóvel respondia pelo movimento eterno que age sobre o conjunto das coisas. Desapareceu então a exigência de um termo final da cadeia dos fenômenos, pois, nas palavras de Renouvier, “esse motor, não sendo uma causa eficiente, mas apenas final, oferecia o ponto de parada exigido pela causa última dos movimentos, mas não pelos próprios movimentos, dos quais Aristóteles via a sucessão no passado como não tendo começo" (idem, p. 103). Essa concepção de eternidade do mundo pressupõe, em cada momento dado, uma sucessão de fenômenos transcorridos em seu conjunto total, mas exclui a possibilidade de se percorrer ou se reconstituir a cadeia completa 
no sentido ascendente.

Do ponto de vista da extensão, diz Renouvier, sempre foi mais fácil pensar um mundo finito, fazendo abstração do espaço vazio que ficaria para além. Do ponto de vista do tempo, no entanto, não era tão simples abstrair o período anterior à existência dos fenômenos e representar o ponto de partida. Nas palavras dele, "a questão do lugar é mais fácil de afastar do que a questão da origem, e a ideia de ubiquidade ganhou muito menos importância na especulação do que a ideia de eternidade, que lhe é paralela" (idem, p. 107). Para o filósofo, porém, a ideia de infinito é contraditória, pois apresenta imagens de relações irrealizáveis, como a de que um corpo possa estar simultaneamente em diferentes lugares (idem, pp. 109110). Como escreve Fedi, "para analisar bem a maneira pela qual Renouvier não cessará de colocar o problema, pode-se dizer que, ao rejeitar o infinito, ele pretende se afastar de um horizonte de pensamento onde se perfilam todo tipo de 'aberrações místicas"” (Fedi, 1998, p. 10). O dilema do infinito se apresenta como segue:

Ou os fenômenos podem, no espaço (atualmente) e no tempo (passado), ser dados, reais e distintos e, no entanto, não formar todos determinados e números, quando são considerados em conjunto; e compostos de elementos reais e distintos podem ser constituídos sem que sua soma dada seja um número determinável;

Ou toda multidão dada de fenômenos dados e distintos forma um todo que é um número determinado (Renouvier, 1901a, p. 124-125, itálicos do autor).

O quarto dilema, entre determinismo e liberdade, é especialmente importante para compreender o pensamento de Renouvier. ${ }^{8}$ Ele define o determinismo como a hipótese do encadeamento universal e rígido dos fenômenos, em que os estados antecedentes produzem um único consequente, sem possibilidades distintas. Isso significa que, nas palavras dele, "cada fenômeno, tomado em particular, é, em cada em instante, o único cuja produção tenha sido possível nas suas circunstâncias, e que jamais há outra possibilidade em todas as coisas senão o necessário” (idem, p. 126). A existência da liberdade se liga à contingência, isto é, à produção de fenômenos de modo não necessário. Segundo essa hipótese, diz Renouvier, existe "um componente de indeterminismo nas relações dos fenômenos sucessivos, e os agentes naturais têm o poder de produzir certos atos ou atos diferentes, e os atos contrários, nas mesmas circunstâncias dadas" (idem, pp. 126-127).

Para o filósofo, o determinismo implica a predeterminação universal de todos os fenômenos, na medida em que pressupõe que cada estado de coisas dado resulta de causas antecedentes e é, por sua vez, a causa necessária dos estados futuros. Isso significa que todas as séries causais estão vinculadas de alguma maneira, e que efeitos aparentemente acidentais são, na verdade, necessários. Como ele escreve,

8 Para uma discussão sobre a liberdade em Renouvier, cf.: Logue, 1993. 
“mas a hipótese de uma independência mútua das duas séries não é admissível, assim que se admite a predeterminação dos termos de cada uma delas em particular, para o momento em que elas se encontram" (idem, pp. 127-128). Nesse sentido, potência e ato são idênticos no mundo, isto é, tudo o que foi, é e será está eternamente presente em tudo como fato e como possibilidade (idem, p. 129). A tese das causas contingentes, por seu turno, introduz a ideia de um futuro indeterminado e a possibilidade de fenômenos diversos.

A visão de Renouvier sobre esse dilema sofreu influência da obra Jules Lequier, seu mestre e amigo, ${ }^{9}$ que teria defendido o livre-arbítrio sem ignorar seus problemas teóricos. De um lado, Lequier entenderia os argumentos deterministas como convincentes, mas a impossibilidade da contingência como não demonstrada. De outro, teria consciência das sérias inconsistências lógicas das defesas da liberdade (idem, pp. 170-171). Os filósofos entendiam que, no fim de contas, os dois lados se fundam em crenças e que a questão não pode ser resolvida por argumentos ou análises abstratas. A exposição do dilema feita por Renouvier segue as teses de Lequier, que o apresenta com relação ao conhecimento e ao ser. No tocante ao conhecer, o determinismo pressupõe que os raciocínios sobre quaisquer assuntos são encadeados necessariamente. Nesse caso, diz Renouvier, o determinismo deverá ser tomado como opinião filosófica verdadeira, mas seu contrário também deverá, pois é a mesma lei que determina necessariamente ambas as opiniões. Assim, a afirmação da liberdade deverá ser aceita como opinião necessária pelo defensor do determinismo. Por seu turno, para os defensores da liberdade, a afirmação do livre-arbítrio é um ato livre, tanto quanto sua negação e, como resultado, o determinismo se contradiz, enquanto a liberdade não o faz. Por conseguinte, diz Renouvier, é preciso decidirse entre liberdade e necessidade, sabendo-se que o determinismo não garante sua própria verdade e que defender a liberdade é a atitude moralmente mais favorável. Citando Lequier, ele escreve: “A liberdade é a condição do conhecimento" (idem, p.176, itálicos do autor).

No tocante ao ser, o dilema se refere à causa na sucessão dos fenômenos. Conforme Renouvier, a tese central do determinismo acaba por remeter a um regresso ao infinito na busca das causas e, no fim das contas, ao mesmo dilema do infinito. Em função disso, paralelamente à questão da contingência, o dilema passa a se referir também à existência ou não de uma causa primeira do mundo, apresentando uma disjunção entre a afirmação de uma causa prima e a prolongação indefinida da busca das causas (idem, p. 179). Para o filósofo, é necessário evitar-se uma busca infinita e afirmar-se a existência de uma causa primeira. Como explica Fedi, "ao admitir o fato de uma causa primeira, Renouvier evita a tese, contraditória para ele, da regressão infinita dos fenômenos" (Fedi, 1998, p. 17). O dilema do determinismo é então o

9 Sobre a ligação entre Renouvier e Lequier, cf.: Blais, 2014. 
seguinte:

Ou a série dos fenômenos não teve começo, mas todo fenômeno, e sempre, teve antecedentes que encerraram sua causa suficiente, e nenhum fenômeno pôde ou pode entrar na série senão como efeito de tal causa suficiente;

Ou a série dos fenômenos teve começo, a causa primeira dos fenômenos é uma causa que não foi efeito de uma ou de várias que a tenham precedido na ordem do tempo, e são possíveis fenômenos cuja causa suficiente não esteja dada nos fenômenos anteriores (Renouvier, 1901a, p. 182, itálicos do autor).

O último dilema discutido por Renouvier trata da dicotomia entre coisa e pessoa, em que aparecem ideias de uma fase ulterior de seu pensamento, o personalismo. Na opinião de Fedi, "a partir daí, surge uma terceira fase, interna ao neocriticismo, que começa em torno de 1885 e que tende a direcionar o neocriticismo a um 'personalismo'” (Fedi, 1998, p. 16). Renouvier afirma que, na Antiguidade, os indivíduos tendiam a representar sua própria natureza como essência das coisas e a supor ações voluntárias nos fenômenos. A ideia de personalidade se aliava ao antropomorfismo mitológico, em que deuses eram apresentados como fontes de qualidades e de efeitos que se manifestavam nos fenômenos naturais. Ao longo da História, a ideia de personalidade foi gradativamente se aproximando da ideia de divindade, ao mesmo tempo em que se opunha e se afastava da ideia de coisa. Renouvier destaca que foi necessária uma abstração na investigação antiga, para que se separasse a ideia do fenômeno da sua causa e de toda atividade voluntária. Nesse processo, o universo inteiro, incluindo os seres humanos, passou a ser identificado com a coisa, e a pessoa passou a ser considerada uma abstração. Desapareceu então a concepção, retomada apenas com o idealismo moderno, de que nada é inteligível sem a consciência. Para o filósofo, porém, a pessoa é a origem real e o fim supremo da existência. Nas palavras dele, "a consciência é, com efeito, no homem que percebe os fenômenos, a condição das coisas que lhes são representadas, pois, se ela lhe é removida, o mundo desaparece para ele" (Renouvier, 1901a, p. 189).

$\mathrm{O}$ dilema correspondente ganha a forma de uma alternativa entre o consciente e o inconsciente como princípios do mundo, e se manifesta na História da Filosofia como a dicotomia entre a personalidade ou a coisa como ser primeiro. No fim de contas, esse dilema resumiria todos os outros, pois se trata de encontrar a sede e o princípio do mundo, os quais, num caso, são buscados nas coisas e, no outro, na consciência. Os realismos, que se identificam com o impersonalismo, buscariam deduzir a consciência a partir da coisa por meio de doutrinas da substância, da emanação e da evolução (idem, p. 238). No personalismo, por sua vez, a consciência humana é tomada como o único fundamento do conhecimento e do ser que a ele se refere. Na interpretação de Gabriel Séailles, essas ideias representam uma transformação no espírito e no método de Renouvier, tornando-se uma segunda 
filosofia, oposta ao neocriticismo em alguns aspectos. Na sua obra La philosophie de Charles Renouvier (1905), esse autor escreve:

Ele tende a um verdadeiro dogmatismo, aborda e pretende resolver as questões da origem, ele aí chega, enfim, por um retorno aos procedimentos da metafísica, a explicar o mundo visível pelo mundo invisível, que deveria ser apenas seu prolongamento hipotético e postulado (Séailles, 1905, p. 362).

De fato, ideias e postulados metafísicos são reabilitados nessa fase do pensamento de Renouvier. Na tese do personalismo, ele propõe sem mais que a ideia de Deus seja admitida como constituindo uma entidade que abarca a origem e o fim predeterminado do mundo. ${ }^{10} \mathrm{O}$ personalismo, diz ele, procura harmonizar o aspecto moral do indivíduo com a causalidade e a finalidade universais, e toma Deus e o Humano como postulados da consciência individual. Nesse sentido, ele escreve, a consciência é "a unidade viva do individual e do universal, cuja mais alta expressão que nos é conhecida, no estado múltiplo, é a pessoa humana, e cujo ideal de unidade e de perfeição individual é Deus" (1901a, p. 244). Para ele, o desenvolvimento dessa tese engendraria uma monadologia em uma harmonia preestabelecida, excluindo, porém, o determinismo universal. O último dilema é então colocado nos seguintes termos:

Ou Deus, ou a coisa sem Deus,

Ou o Homem, ou seres totalmente nulos, dos quais nenhum atinge a ideia completa e realizada de Homem.

Deus aut non Deus, Homo aut non Homo (idem, p. 246, itálicos do autor).

\section{Conclusão}

A análise realizada por Renouvier tem como fio condutor a aplicação das noções metafísicas de condição, qualidade, quantidade, personalidade e causalidade ao mundo. Ele divide a História da Filosofia em dois grandes campos, representados pelo neocriticismo e pelo realismo, que teria originado teorias permeadas de inconsistências, vícios lógicos e contradições, em virtude de desconsiderarem o princípio de relatividade. Conforme Renouvier, todos os dilemas apresentariam uma alternativa entre a negação e a afirmação do princípio, mas, no nosso entendimento, nem todos eles se caracterizam assim. O dilema do incondicionado remete à dificuldade de definir esse ser e de deduzir dele o condicionado, sem se recorrer a condições. Se o incondicionado não é nada, nada se poderá derivar dele; se ele

10 Renouvier foi educado no cristianismo, mas lutou contra a Igreja na França e se aproximou do protestantismo. Para sua relação com a religião, cf. Arnal (1907); Méry (1963). 
é algo, terá de ser algo determinado, isto é condicionado. Trata-se de um vício da própria questão, que Renouvier mesmo considera um "vício lógico inerente". Outro é o caso do dilema da substância que, segundo nos parece, surge de fato por uma violação ao princípio de relatividade. Com efeito, nem a consciência empírica, nem os corpos, enquanto sujeitos reais, podem ser compreendidos a partir de qualidades em si, abstratas, isto é, como substâncias, pois isso contradiz o estabelecido pelo princípio de relatividade.

O dilema do infinito também parece não se ligar a uma violação ao princípio de relatividade, mas à contradição intrínseca representada pela ideia de infinito atual. Renouvier admite a infinitude como possibilidade indefinida de aumento em uma grandeza, mas a lei do número impede a realização material dessa possibilidade nos fenômenos. De acordo com isso, todo fenômeno real e distinto deverá ser finito em extensão e número. Cassirer observa, sobre esse ponto, que a lei do número é um corolário do princípio de não contradição (1912, p. 87). Por sua vez, o dilema do determinismo também não se relaciona com o princípio de relatividade e, a rigor, é apresentado apenas no tocante ao conhecer. De fato, advogar o determinismo no tocante ao conhecimento implica admitir também a necessidade da opinião que defende a liberdade, o que é uma autocontradição. No dilema do determinismo com relação ao ser, não se trata de nenhuma falha na tese determinista, mas de uma necessidade arbitrária de se parar na busca das causas e apontar a causa prima. Por fim, o problema apontado por Renouvier no dilema do impersonalismo é o de se dar ao mundo uma origem e um fim condizentes com a dignidade humana. Nada tem a ver com o princípio de relatividade, mas com o aspecto moral da humanidade, que seria prejudicado caso o mundo tivesse sua criação e finalidade ligadas a um princípio inconsciente. Por isso, o filósofo aponta Deus e o Humano como postulados.

É importante acompanharmos a argumentação de Renouvier sem perder de vista as questões de fundo que são o fio condutor de sua análise. No primeiro dilema, trata-se da necessidade de fornecer sustentação ao mundo condicionado, entendido como precário e transitório. O condicionado sempre devém, nunca é, e, sem um ponto de apoio, em última instância, não existe. No dilema da substância, a questão em jogo é a de saber qual é a constituição intrínseca dos fenômenos, aquela coisa que poderia ser seu substrato e sua essência. Não à toa, a primeira definição dela foi a de uma matéria difusamente pensada, de onde os corpos teriam saído. No dilema do infinito, o problema metafísico subjacente é o de aplicar a noção de infinitude ao mundo material. 0 mundo, como todo objeto, parece ter um início no tempo e limites no espaço, mas a dificuldade de encontrá-los sugere a necessidade do conceito de infinito que, no entanto, sempre traz problemas quando confrontado com a realidade concreta. No dilema do determinismo, a questão debatida é a de saber se a contingência é possível, dada a experiência universal da causalidade. 
Parece certo que a causalidade e o determinismo existam, mas também que a contingência tenha algum papel no mundo. Estabelecer o alcance e o escopo de cada qual é uma questão metafísica fundamental. No último dilema, do impersonalismo, trata-se determinar o tipo de entidade que estaria na origem do mundo, se um ente consciente ou inconsciente. Nesse caso, parte-se da tese de que o mundo tem origem e finalidade, cuja natureza então se disputa.

Independentemente da posição que Renouvier adota perante os dilemas, seu procedimento é interessante e fecundo, porque permite acompanhar diversas filosofias e argumentações, sem perder de vista o telos que as guiava, as unia e separava. Esse telos, segundo pensamos, são as questões de fundo, problemas genuínos cujas tentativas de solução de fato conduziram frequentemente a dilemas, aporias e paradoxos. Para o filósofo, a contradição mútua e os erros na História da Filosofia são inexpugnáveis, pois o entendimento é tão passível de engano quanto de alcançar a verdade. Além disso, o conhecimento e a certeza são dependentes do intelecto humano e do individual. Longe de ser levado à desesperança, Renouvier acredita que o neocriticismo pode conduzir à verdade e parte em busca dela com seu princípio de relatividade, inspirado na crítica kantiana. Para nós, o procedimento de rastrear as questões puras e simples que movimentam a História da Filosofia é particularmente interessante, sobretudo em tempos nos quais inumeráveis discursos se sobrepõem e parece não haver diferença entre verdade e falsidade. Os problemas fundamentais são sempre pontos fixos, com os quais podemos comparar todas as soluções.

\section{Referências}

Arnal, A. (1907). La philosophie religieuse de Charles Renouvier. Paris: Fischbacher. Blais, M.-C. (2000). Au principe de la République. Le cas Renouvier. Paris: Gallimard. Blais, M.-C. (2014). Postuler la liberté? Ce que la philosophie républicaine de Renouvier doit à Jules Lequier. Texto apresentado no Colloque Jules Lequier, realizado pela associação Amis de Jules Lequier, pela République des Savoirs e o Centre International d'Étude de la Philosophie Française Contemporaine, na École Normale Supérieur, Paris, em 30 de setembro de 2014.

Cassirer, E. (1912). Das Problem des Unendlichen und Renouviers “Gesetz der Zahl”. In: Cohen, H. Philosophische Abhandlungen. Berlin: Bruno Cassirer.

Fedi, L. (1998). Le problème de la conaissance dans la philosophie de Charles Renouvier. Paris: L'Harmattan.

Fedi, L. (2002). Philosopher et républicaniser: la Critique philosophique de Renouvier et Pillon, 1872-1889. Romantisme, 115, pp. 65-82.

Hamelin, O. (1899). La philosophie analytique de l'histoire de M. Renouvier. L'Anée Philosophique, 9, pp. 21-48.

Logue, W. (1993). Charles Renouvier, philosopher of liberty. Baton Rouge: Lousiana 
State UP.

Méry, M. (1963). La critique du christianisme chez Renouvier. 2 vols. $2^{\mathrm{a}}$ ed. Paris: Ophrys-Gap.

Milhaud, G. (1927). La philosophie de Charles Renouvier. Paris: Vrin.

Renouvier, C. \& Pillon, F. (1872-1889). Critique philosophique, politique, scientifique et littéraire. Paris: Au Bureau de la Critique Philosophique.

Renouvier, C., Bellouard, H., Benoit (du Rhône), Charassin, F., Chouippe, A., Erdan, Fauvety, C., et al. (1851). Du gouvernement direct. Organisation communale et centrale de la République. Paris: Librairie Républicaine de la liberté de penser.

Renouvier, C. (1842). Manuel de philosophie moderne. Paris: Paulin.

Renouvier, C. (1844). Manuel de philosophie ancienne. Paris: Paulin.

Renouvier, C. (1848). Manuel républicain de l'homme et du citoyen. Paris: Pagnerre.

Renouvier, C. (1885-1886). Esquisse d'une classification systématique des doctrines philosophiques. 2 vol. Paris: Au Bureau de la Critique Philosophique.

Renouvier, C. (1896). Essais de critique générale. IV. Introduction a la philosophie analytique de l'histoire. Paris: Ernest Leroux.

Renouvier, C. (1899). Du principe de relativité. L'Anée Philosophique, 9, pp. 1-19.

Renouvier, C. (1901a). Les dilemmes de la métaphysique pure. Paris: Alcan, 1927.

Renouvier, C. (1901b). Histoire et solution des problèmes métaphysiques. Paris: Alcan.

Renouvier, C. (1906). Critique de la doctrine de Kant. Paris: Alcan.

Schmaus, W. (2007). Renouvier and the method of hypothesis. Studies in History and Philosophy of Science, 38, pp. 132-148.

Séailles, G. (1905). La philosophie de Charles Renouvier. Introduction a l'étude du néo-criticisme. Paris: Alcan.

Verneaux, R. (1945). Renouvier, disciple et critique de Kant. Paris: Vrin.

Recebido em: 29.08.2019

Aceito em: 05.03.2020

Esta obra está licenciada com uma Licença Creative Commons Atribuição-NãoComercial-

-Compartilhalgual 4.0 Internacional.

https://creativecommons.org/licenses/by-nc-sa/4.0/

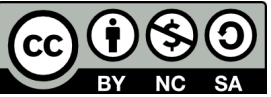

